\title{
Why is road safety in the U.S. not on par with Sweden, the U.K., and the Netherlands? Lessons to be learned
}

\author{
Juha Luoma • Michael Sivak
}

Received: 11 September 2013 / Accepted: 10 January 2014 / Published online: 25 January 2014

(C) The Author(s) 2014. This article is published with open access at SpringerLink.com

\begin{abstract}
Purpose This study compared road safety and related factors in the U.S. with those in Sweden, the United Kingdom, and the Netherlands (which are among the best-performing countries), in order to identify actions most likely to produce casualty reductions in the U.S.

Method The reviewed topics were basic country statistics, road fatalities and various fatality rates, and selected roadsafety issues.

Results The main differences concerned structural and cultural factors (such as vehicle distance driven), and procedural factors (such as alcohol-impaired driving, exceeding speed limits, and use of seat belts).

Conclusions The main recommendations for improving road safety in the U.S. are as follows: (1) lower states' BAC limits, and encourage the use of alcohol ignition interlocks (2) reexamine the current speed-limit policies and improve speed enforcement, (3) implement primary seat-belt-wearing laws in each state that would cover both front and rear occupants, and reward vehicle manufacturers for installation of advanced seat-belt reminders, and (4) reconsider road-safety target setting so that the focus is on reducing fatalities and not on reducing fatality rate per distance driven, and (5) consider new strategies to reduce vehicle distance driven.
\end{abstract}

Keywords Countermeasures · Driver behavior · Fatality · Seat belt $\cdot$ Speeding $\cdot$ Young drivers $\cdot$ Alcohol

J. Luoma $(\bowtie)$

VTT Technical Research Centre of Finland, P.O. Box 1000,

02044 Espoo, Finland

e-mail: juha.luoma@vtt.fi

M. Sivak

Transportation Research Institute, The University of Michigan, Ann Arbor, MI 48109-2150, USA

\section{Introduction}

Despite recent major improvements in road safety in the U.S. [30], the current safety level in terms of fatalities per population is far below the level of the best-performing countries [24]. Therefore, it should be instructive to compare factors affecting road safety in the U.S. and the best-performing countries. This type of benchmarking can be beneficial as it can reveal differences at several relevant levels [41]: (1) structure and culture, (2) safety measures and programs, (3) safety performance indicators, and (4) number of fatalities and injured persons. A comparison of the U.S. with countries that do not substantially differ in terms of economic situation, motorization, etc. will yield the most valuable information.

Several comparisons of this type have been carried out in Europe under the SUNflower umbrella. These studies started with a comparison of road-safety developments in Sweden, the United Kingdom and the Netherlands (the SUN countries), which are among the best-performing countries in the world in terms of road safety [17]. That study determined the underlying elements in the road-safety policies and programs of the countries, and it investigated factors that make them particularly effective. The results showed that the targeted roadsafety policy areas were rather similar, but the policies that were implemented differed. This implies that there is no single approach to achieving first-class road-safety results.

The present study was designed to compare road safety and related factors in the U.S. with those in Sweden, the United Kingdom (U.K.), and the Netherlands, in order to identify actions most likely to produce casualty reductions in the U.S.

\section{Approach}

To compare road safety in the U.S. and the SUN countries, the following topics were examined by country: (1) background 
statistics, (2) road fatalities and main fatality rates, and (3) five selected road-safety issues.

The primary measures for international road-safety comparisons are road fatalities and/or injuries per population, because they are the most appropriate measures to show the total harm resulting from road crashes [21, 28, 31]. Such measures are compatible with the measures used in the public-health domain [28], such as mortality per population from illnesses and other causes [44].

Other measures include fatality rates per distance driven, per registered vehicle, per licensed driver, and per trip. They have relevance in road-safety activities and each of them has proper areas of application [28]. However, none of them can measure the total harm, as a rate per population can.

The study was limited to fatal crashes and fatalities, because there are no major differences in the countries of interest in the definitions of road fatalities [15]. In contrast, the definitions of injured persons by country vary too much to make reliable comparisons. In addition, it is well known that crashes involving nonfatal injuries are underreported [5]. To avoid problems with short-term and random variations in crash statistics, data for five recent years (2006-2010) were used, whenever available.

Crash and exposure information was retrieved from international sources such as the IRTAD database [15] and publications of international organizations (e.g., OECD/ITF, WHO), if available. This approach aimed to avoid differences in the reporting systems of the countries that could be responsible for some of the obtained findings. Additional information was collected from national sources.

The final topics to be covered in this paper are based on our earlier study [29], which examined five factors that are important to road safety in the U.S. The factors included were alcohol-impaired driving, exceeding posted speed limits, not wearing seat belts, visibility problems in nighttime driving, and young driver problems. These factors have garnered almost universal support as being among the major factors in road safety. Our earlier study [29] showed that there is a variety of opportunities to make substantial gains in road safety using existing knowledge about (1) of the importance of each of these factors, (2) known effective countermeasures (both policy and technology based), and (3) impediments to the implementation of these countermeasures in the U.S. In the present study, these factors will be discussed in terms of the differences in driver behavior, crashes, and countermeasures in the U.S. and the SUN countries.

\section{Background statistics}

Table 1 lists selected background statistics by country. The main difference between the U.S. and the SUN countries is the size of the U.S., which is larger in terms of both population
Table 1 Selected background statistics by country

\begin{tabular}{|c|c|c|c|c|}
\hline Background statistics & U.S. & Sweden & U.K. & Netherlands \\
\hline $\begin{array}{l}\text { Population, } \\
\text { thousand }(2010)^{\mathrm{a}}\end{array}$ & 310,384 & 9.380 & 62,036 & 16,613 \\
\hline $\begin{array}{l}\text { Area, thousand } \\
\mathrm{km}^{2}(2010)^{\mathrm{a}}\end{array}$ & $9,629.1$ & 450.3 & 255.4 & 37.4 \\
\hline $\begin{array}{l}\text { Population density, } \\
\text { inhabitants per } \\
\mathrm{km}^{2}(2010)^{\mathrm{a}}\end{array}$ & 32.2 & 20.8 & 255.4 & 444.7 \\
\hline \multicolumn{5}{|l|}{$\begin{array}{l}\text { Population age } \\
\quad \text { composition }(2010)^{\mathrm{b}}\end{array}$} \\
\hline$\leq 14$ years & $20 \%$ & $17 \%$ & $17 \%$ & $18 \%$ \\
\hline $15-64$ years & $67 \%$ & $65 \%$ & $66 \%$ & $67 \%$ \\
\hline$\geq 65$ years & $13 \%$ & $18 \%$ & $17 \%$ & $15 \%$ \\
\hline $\begin{array}{l}\text { Gross domestic product } \\
\text { per capita (PPP), US\$ } \\
(2010)^{\mathrm{c}}\end{array}$ & 46,805 & 39,479 & 35,692 & 42,230 \\
\hline \multicolumn{5}{|l|}{${ }^{\mathrm{a}}$ [39] } \\
\hline \multicolumn{5}{|l|}{${ }^{\mathrm{b}}[15]$} \\
\hline${ }^{\mathrm{c}}[40]$ & & & & \\
\hline
\end{tabular}

and land area. Consequently, the variability of factors related to driving and traffic crashes in the U.S. is larger than in the SUN countries. In addition, it is likely that there is much more long-distance travel in the U.S in comparison with the SUN countries.

In terms of population density, the U.S. is within the range of the SUN countries. Population in the U.S. is somewhat younger and wealthier than in the SUN countries.

\section{Main fatality rates and current road-safety targets}

This section presents the number of road fatalities and selected fatality rates for the four countries of interest. In addition, current road-safety targets will be reviewed.

\subsection{Road fatalities and main fatality rates}

Table 2 shows the number of fatalities, population, motor vehicles, and vehicle distance driven by country. The data indicate that, between 2006 and 2010, there was a substantial reduction in road fatalities in each country. Fatality rates based on the data in Table 2 are presented in Table 3.

Table 3 shows that every rate is substantially lower for the SUN countries than for the U.S. (on average $66 \%$ lower per population, $49 \%$ lower per motor vehicles, and $35 \%$ lower per vehicle distance driven).

\subsection{Road-safety targets}

In the U.S., the fatality-rate goal for 2012 was 1.05 fatalities per 100 million vehicle-miles (as compared to the actual rate 
Table 2 Number of fatalities, population, motor vehicles (excluding mopeds), and vehicle distance driven by country [15]

\begin{tabular}{|c|c|c|c|c|c|c|}
\hline Measure & Year & U.S. & Sweden & U.K. & Netherlands & SUN total \\
\hline \multirow[t]{6}{*}{ Fatalities } & 2006 & 42,708 & 445 & 3,298 & 730 & 4,473 \\
\hline & 2007 & 41,259 & 471 & 3,059 & 709 & 4,239 \\
\hline & 2008 & 37,423 & 397 & 2,645 & 677 & 3,719 \\
\hline & 2009 & 33,883 & 358 & 2,337 & 644 & 3,339 \\
\hline & 2010 & 32,885 & 266 & 1,905 & 537 & 2,708 \\
\hline & Average & 37,632 & 387 & 2,649 & 659 & 3,696 \\
\hline Population $\left(10^{3}\right)$ & $2006-2010^{\mathrm{a}}$ & 303,965 & 9,188 & 61,408 & 16,436 & 87,032 \\
\hline Vehicles $\left(10^{3}\right)$ & $2006-2010^{\mathrm{a}}$ & 256,944 & 5,351 & 34,850 & 9,045 & 49,246 \\
\hline Vehicle distance driven $\left(10^{6} \mathrm{~km}\right)$ & 2009 & $4,758,450$ & 81,444 & 516,007 & 126,966 & 724,417 \\
\hline Vehicle distance driven per person & 2009 & 15,511 & 8,799 & 8,345 & 7,701 & 8,272 \\
\hline
\end{tabular}

${ }^{a}$ Average for the given years

for 2010 of 1.10) [24]. The current Swedish interim target for fatalities is a $50 \%$ reduction between 2007 and 2020 [3]. A corresponding target for serious injuries is a $25 \%$ reduction. In the U.K., there are separate road-safety strategies for Great Britain and Northern Ireland [3]: In Great Britain, forecasted scenarios are used and there are no specific road-safety targets, while Northern Ireland has road-safety targets, including a fatality reduction of $60 \%$ for 2020 in comparison with the average for 2004-2008. The current Dutch road-safety targets for 2020 include a maximum of 580 fatalities and 10,600 serious injuries [24]. In comparison with the U.S., the roadsafety targets of Sweden, Northern Ireland, and the Netherlands are more direct because the targets measure the total harm resulted from road crashes.

\section{Five selected road-safety issues}

In this section, five selected road-safety issues will be examined in detail. The issues included are alcohol-impaired driving, exceeding speed limits, not wearing seat belts, nighttime driving, and young drivers [29].

\subsection{Alcohol-impaired driving}

Alcohol-impaired driving has been one of the most severe and long-lasting problems of road safety throughout the world. The extent of alcohol consumption is typically the first proxy for estimating the problem of alcohol-impaired driving. The data from WHO [43] for 2003-2005 show that average alcohol consumption (in liters of pure alcohol) per capita for persons 15 years of age or older was highest in the U.K. (13.4), followed by Sweden (10.3), the Netherlands (10.1), and the U.S. (9.4). These results suggest that alcohol consumption is slightly lower in the U.S. than in the SUN countries.

Table 4 shows the general legal BAC limits in the U.S. and the SUN countries. The highest limit is in the U.S. and U.K. $(0.8 \mathrm{~g} / \mathrm{l})$, followed by the Netherlands $(0.5 \mathrm{~g} / \mathrm{l})$ and Sweden $(0.2 \mathrm{~g} / \mathrm{l})$. Given that the risk of a crash at $0.8 \mathrm{~g} / \mathrm{l}$ is about twice that at $0.5 \mathrm{~g} / 1$ [2], lowering the limit in the U.S. would result in some safety benefits. Specifically, it has been estimated that such a lowering reduces alcohol-related fatal crashes by $2 \%$ [5].

The prevalence of driving under the influence of alcohol on weekend nights is currently estimated to be $3 \%$ in the U.S. [24] and 2.4\% in the Netherlands [35]. No corresponding information is available for Sweden or the U.K.

Overall, assessments of the proportion of alcohol-related crashes lack reliable information. This is the case because not all road users involved in crashes are tested for alcohol [3]. Thus, alcohol-related crashes are usually underreported. With that caveat and different legal limits in mind, country reports collected by WHO [42] indicate that the proportion of road fatalities involving (but not necessarily attributable to) alcohol was $32 \%$ for the U.S., $25 \%$ for the Netherlands, $20 \%$ for Sweden, and $17 \%$ for the U.K.

Table 3 Fatality rate per population, number of motor vehicles (excluding mopeds), and vehicle distance driven by country (2006-2010)

\begin{tabular}{llllll}
\hline Fatality rate & U.S. & Sweden & U.K. & Netherlands & SUN average \\
\hline Per million people & 123.8 & 42.2 & 43.1 & 40.1 & 42.5 \\
Per million motor vehicles & 146.5 & 72.4 & 76.0 & 72.9 & 75.0 \\
Per billion km driven $^{\mathrm{a}}$ & 7.1 & 4.4 & 4.5 & 5.1 & 4.6 \\
\hline
\end{tabular}


Table 4 General BAC limit(s) (g/l) by country [24]

\begin{tabular}{llll}
\hline U.S. & Sweden & U.K. & Netherlands \\
\hline $\begin{array}{l}0.8 \text { (0.2 for drivers }<21 \\
\begin{array}{l}\text { years; } 0.4 \text { for } \\
\text { professional drivers })\end{array}\end{array}$ & 0.2 & 0.8 & $\begin{array}{c}0.5(0.0 \text { for drivers }<20 \\
\text { years and repeat offenders } \\
\text { since } 2011 \text { [earlier } 0.3])\end{array}$ \\
\hline
\end{tabular}

Random breath testing means that the police are allowed to test drivers' breath without having any suspicion. Random breath testing is generally recognized as one of the most effective countermeasures against alcohol-impaired driving [33]. Random breath testing is implemented in the Netherlands and Sweden, but not in the U.K. and the U.S.

The results of face-to-face interviews of European drivers show that the proportion of drivers who have encountered (any sort of) alcohol checks over the previous 3 years was $41 \%$ in Sweden, $37 \%$ in the Netherlands, and $9 \%$ in the U.K. [27]. Consequently, drivers' subjective risk of being caught is relative high in the Netherlands and in Sweden but not in the U.K. Furthermore, it has been found in the Netherlands that each doubling of the number of random breath tests since 1986 was associated with a $25 \%$ decrease in drink-driving offenses [33]. Between 1985 and 2005, the proportion of drink-driving offenders decreased by two thirds. In Sweden, the proportion of injury crashes involving drunk drivers was reduced from 14 to $9 \%$ after the introduction of random breath testing in the 1970s [33].

Alcohol ignition interlock is a relatively new countermeasure to reduce alcohol-impaired driving. The device utilizes breath-alcohol sensors to confirm that a driver's BAC is below a specified limit before the vehicle can be started. In Sweden, for example, it has been found that alcohol ignition interlock programs have favorable effects compared to conventional license revocation and would be useful tools for attaining changes in the alcohol and driving habits of offenders [1].

These devices are currently used in certain conditions in the U.S. and the SUN countries. Specifically, all U.S. states have laws either requiring interlocks for certain offenders or allowing courts to order interlocks at their discretion [12]. In Sweden, alcohol ignition interlocks are used for repeat offenders and in various company cars. The total number of interlocks was recently estimated at a minimum of 55,000 or more [19]. In the Netherlands, an alcohol-interlock program for serious alcohol offenders was introduced in 2011 [34]. No information was available for the U.K. Recently, the U.S. National Transportation Safety Board recommended ignition interlocks for all first-time offenders [22].

\subsection{Exceeding speed limits}

Many countries provide information about the frequency of speeding-related crashes. However, that information is not very relevant, because speed is a contributing factor in most crashes. Therefore, we focus here on speed limits, drivers exceeding the limit, and automatic speed enforcement.

Table 5 lists the posted speed limits for passenger vehicles by road type and country. The maximum speed limit is highest in the U.S. for all road types (for motorways about the same as in the Netherlands). This difference is likely to be important, because the highest limit is likely used most frequently.

Special speed limits for heavy vehicles are used in the SUN countries, but only in ten states in the U.S. [23]. Speed limiters are compulsory for heavy vehicles in the SUN countries [8], but not in the U.S.

The proportion of light-duty vehicles/passenger cars exceeding the posted limit by road type and country is given in Table 6. (The U.S. data is limited to 30 out of the 50 states, and the frequency of monitoring in the U.S. is generally less than in the SUN countries.) The results show that the U.S. percentages are among the highest for each road type. The most substantial difference exists on urban local and collector streets where $74 \%$ of U.S. drivers exceed the posted speed limits in comparison with $22 \%$ in the U.K. and $45 \%$ in the Netherlands. Unfortunately, the available data are not detailed enough. Therefore, it is assumed that the percentage of exceeding speed limit is out of all vehicles, as opposed to out of only those vehicles that have a possibility to exceed the speed limit because of no congestion.

Automated speed enforcement (ASE) is a system designed to automatically detect vehicles violating speed limits. These types of systems include fixed and mobile speed cameras as well as section control (which measures the average speed over a road section). ASE has been used around the world, and positive effects on speed behavior and safety have been reported overall [36]. One of the main advantages of automated speed enforcement is that it substantially strengthens speed enforcement. In the U.S., speed cameras are used only in 13 states and the District of Columbia [11]. Many programs in the U.S. are restricted to school and constructions zones,

Table 5 Posted speed limits $(\mathrm{km} / \mathrm{h})$ for passenger vehicles

\begin{tabular}{|c|c|c|c|c|}
\hline Road type & U.S. & Sweden & U.K. & Netherlands \\
\hline $\begin{array}{l}\text { Motorways } \\
\text { (limited-access } \\
\text { highways) }\end{array}$ & $\begin{array}{l}104-120 \\
\quad(88-113)^{\mathrm{a}}\end{array}$ & $\begin{array}{l}90-110 \\
\quad(70-90)\end{array}$ & 113 & $120(100)$ \\
\hline Main highways & $88-113$ & $90(70-110)$ & 97 & 100 \\
\hline Rural roads & $88-113$ & $70(90)$ & 97 & $80(60)$ \\
\hline $\begin{array}{l}\text { Urban arterial } \\
\text { roads }\end{array}$ & $48-88$ & $50-70$ & $48(64)$ & $50-70$ \\
\hline $\begin{array}{l}\text { Urban local and } \\
\text { collector streets }\end{array}$ & $40-56$ & $30-50$ & $48(32)$ & $50(30)$ \\
\hline
\end{tabular}

Frequently used limits are listed, with less frequent limits in parentheses [23]

${ }^{\mathrm{a}}$ In urban areas 
Table 6 Percentage of passenger vehicles exceeding the posted limit [23]

\begin{tabular}{lllll}
\hline Road type & U.S. $^{\text {a }}$ & Sweden & U.K. & Netherlands \\
\hline Motorways & $41-66$ & 68 & $20-57$ & $40-45$ \\
Main highways & $52-66$ & 59 & 10 & 20 \\
Rural roads & 47 & 59 & 10 & 45 \\
Urban arterial roads & 73 & N/A & 8 & $50-73$ \\
Urban local and collector streets & 74 & N/A & 22 & 45 \\
\hline
\end{tabular}

a 30 states

residential areas, only when a law-enforcement officer is present, etc. In contrast, all SUN countries apply automatic speed control widely [16]. For example, the number of fixed speed cameras was estimated at about 1,100 in Sweden, 3,500 in the U.K., and 1,600 in the Netherlands [16].

Intelligent speed adaptation (ISA) is an in-car technology that warns the driver about speeding, discourages the driver from speeding, or prevents the driver from exceeding the speed limit. Each SUN country has run several ISA trials [6]. Recently, ISA was included as part of the European New Car Assessment Program [7]. There has not yet been any ISA trial in the U.S. [10].

\subsection{Use of seat belts}

The single most effective technology for reducing injury severity in a motor-vehicle crash is the seat belt [29]. In the SUN countries, the use of seat belts is mandatory for both front and rear occupants of passenger vehicles. In the U.S., there is a mandatory seat-belt law in every state except New Hampshire [13]. However, the laws cover rear occupants in only 26 states and the District of Columbia. In addition, primary laws (i.e., police may stop vehicles solely for beltlaw violations) exist in only 32 out of the 50 states.

In the U.S., the seat-belt usage rates are lower for both sets of seats than in the SUN countries (Table 7). In addition, the use of seat belts in the U.S. is higher in the states with primary belt law $(87 \%)$ than in the states with secondary belt laws (76\%) [24]. The differences between the U.S. and the SUN countries, shown in Table 8, are substantial, especially because non-users are also more likely to get involved in crashes [38]. For example, $51 \%$ of fatally injured passenger-vehicle

Table 7 Use of seat belts by country [24]

\begin{tabular}{lcccc}
\hline Condition & U.S. & Sweden & U.K. & Netherlands \\
\hline Front, driver & $85 \%$ & $97 \%$ & $96 \%$ & $97 \%$ \\
Front, passenger & & $96 \%$ & & \\
Rear, adults & $74 \%$ & $81 \%$ & $90 \%$ & $82 \%$ \\
Rear, children & & $95 \%$ & & \\
\hline
\end{tabular}

occupants in the U.S. in 2010 were unrestrained, although the mean proportion of unbelted drivers and passengers was from 15 to $26 \%$ [24]. Overall, safety benefits obtained from a given percentage increase in seat-belt usage are greatest at the highest percentage levels of usage [38].

Euro NCAP [7] assessment program scores advanced seatbelt reminder systems separately for front and rear occupants. A Swedish study showed that this type of reminder substantially improves belt use [38].

\subsection{Nighttime driving}

Driving at night is substantially riskier than during the day $[25,32]$. Overall, this applies to all countries, but there are differences in exposure to nighttime driving, frequency of vulnerable road users at night, etc.

Table 8 shows road fatalities by light conditions in the four countries of interest. This comparison shows that the overall proportion of nighttime fatalities is highest in the U.S., probably because of relatively more travel at night.

\subsection{Young drivers}

It is a universal finding that young drivers have above average rates of fatal crashes. In most U.S. states, a license to drive unsupervised requires a driver to be at least age 16 [14]. The corresponding minimum age (for passenger cars/light duty vehicles) is 18 in Sweden and the Netherlands, and 17 in the U.K. [3]. Because of these differences in licensure age, fatality rates of two age groups (15-17 years old and 18-20 years old) were examined. Specifically, the proportions of road fatalities of these age groups (out of the total number of road fatalities) were compared with the proportions of persons in the same age groups by country (Fig. 1). If the road users in a given age group are disproportionately likely to be fatally injured in road crashes, the points would fall above the diagonal lines in Fig. 1.

There were two main findings: (1) road fatalities are substantially overrepresented for the 18 to 20 year olds, but only slightly so for the 15 to 17 year olds, and (2) the problem with young drivers is not more severe in the U.S. than in the SUN countries. This finding is somewhat surprising, because it is generally assumed that higher licensing age would be beneficial.

Table 8 Percentage of road fatalities by light conditions (other/unknown not included) [4, 20, 35, 37]

\begin{tabular}{lllll}
\hline Light condition & U.S. & Sweden & U.K. & Netherlands \\
\hline Daylight & 49.0 & 58.3 & 58.1 & 79.8 \\
Dark but lighted & 17.3 & 12.4 & 23.3 & 0.4 \\
Dark & 29.7 & 21.9 & 18.5 & 14.7 \\
Dawn and dusk & 4.0 & 7.4 & N/A & 5.0 \\
\hline
\end{tabular}


Fig. 1 The proportion of road fatalities of 15-17 years old persons (left panel) and 1820 years old persons (right panel) compared with the proportion of the same age group in the population by country, 20062010 [15]

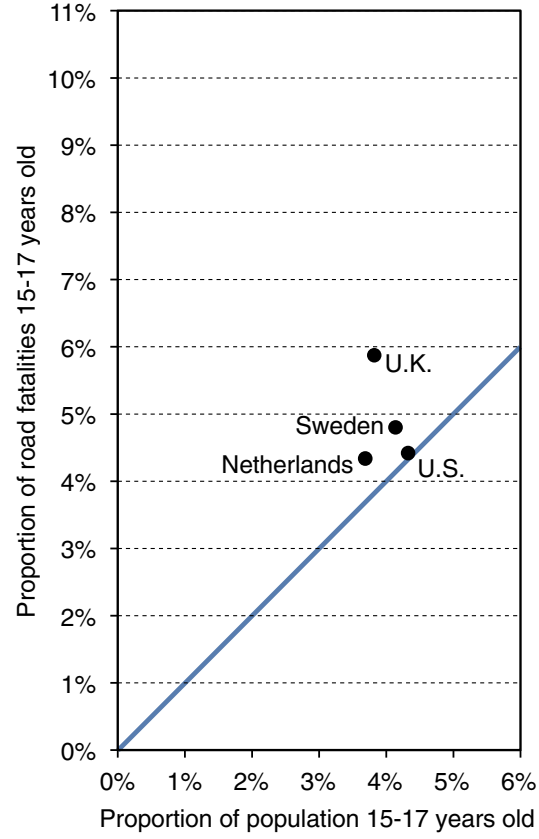

\section{Discussion}

The information in Table 3 showed that the fatality rate per population in the U.S. is about three times the rate in the SUN countries; the corresponding multiples for the fatality rates per vehicle and per distance driven are about 2 and 1.5, respectively. The present analysis indicates that there are three sets of underlying factors that are responsible for these differences: structural, cultural, and procedural. This distinction is of importance because structural and cultural factors are much less amenable to change than procedural factors.

\subsection{Structural and cultural factors}

The U.S. is a much larger country than any of the SUN countries. Furthermore, land use and urban planning differ substantially between the U.S. and Europe. Most U.S. cities were designed in such a way that transportation depends heavily on personal vehicles. Primarily as a consequence of these two factors, the average annual distance driven per capita in the U.S. is about two times the distance in the SUN countries.

These findings imply that fatality rate per distance driven in the U.S. would have to be substantially lower than it is now to achieve the safety level of the SUN countries in terms of fatalities per population. Reducing the vehicle distance driven by improving urban planning, encouraging people to use more public transportation, and more telecommuting would achieve the same goal. This would be beneficial from the environmental point of view as well [18].

The SUN countries are independent countries that can design and implement their own road-safety strategies (although they are member states of the European Union). On the other hand, the U.S. consists of individual states, and the power of the federal government is more limited. A potentially important cultural difference is that Americans might be less willing to accept restricting legislation and enforcement to improve road safety than Europeans $[9,26]$.

\subsection{Procedural factors}

Procedural factors are important because they have the greatest potential of being modifiable in a relatively short time. The present analysis has identified four procedural factors that have likely contributed greatly to the better safety record of the SUN countries as compared with the U.S.

\subsubsection{Alcohol-impaired driving}

The proportion of road fatalities involving alcohol is likely lower in the SUN countries. The BAC limit in Sweden and the Netherlands (but not in the U.K.) is lower than is generally the case in the U.S. Sweden and the Netherlands apply random breath testing.

\subsubsection{Speed}

In the SUN countries speed limits by road type tend to be lower, special speed limits for heavy vehicles are used without exception, speed limiters for heavy vehicles are compulsory, speed cameras are used widely, and the proportion of vehicles that exceed speed limits tends to be smaller. 


\subsubsection{Use of seat belts}

Usage rates in the SUN countries are higher for both front and rear occupants. Seat belts are compulsory and the law covers both front and rear seats. Primary law is the prevailing practice.

\subsubsection{Road-safety target setting}

The underlying logic of the road-safety strategies in the SUN countries differs substantially from that in the U.S. In the SUN countries, the emphasis is on the total number of fatalities (and injuries), and thus on fatality (and injury) rates per population. In contrast, the U.S. focus is on fatality rates per distance driven.

\subsection{Limitations of the study}

This study focused on a selection of factors that have been found to have major effects on road safety. Consequently, it is likely that there are other important differences between the U.S. and the SUN countries of relevance to road safety.

Any cross-cultural study faces differences in road-safety data collection in the examined countries, such as differential reporting of road accidents and fatalities, different specificity of data, and differences in the methods used for the collection of specific data. Such differences were present in this study too.

\section{Recommendations}

The implementation of effective new countermeasures in the U.S. requires raising the awareness of the general public and of the decision makers concerning the much higher safety level in terms of fatalities per population in the bestperforming countries and of the effectiveness of various countermeasures that have been implemented elsewhere. The countermeasures to be recommended would lead to only limited restrictions on driver behavior or privacy, but would likely result in substantial benefits in terms of human life saved, suffering avoided, and expenses avoided.

Based on the present analysis, the following is a list of key recommendations for improving road safety in the U.S.

- Lower states' BAC limits and encourage the use of alcohol ignition interlocks. Random breath testing would be highly beneficial too, but its introduction would require a court action that would exempt it from the constitutional prohibition against random search without probable cause.

- Reexamine the current speed limit policies (especially in urban areas) and improve speed enforcement by a widescale implementation of speed cameras and/or intelligent speed adaptation.
- Implement in each state primary seat-belt-wearing laws that would cover both front and rear occupants. In addition, reward OEMs for installation of advanced seat-belt reminders.

- Reconsider road-safety target setting so that the goal is given in terms of the number of reduced fatalities, with supplementary goals in terms of serious injuries and other safety indicators.

- Consider new strategies to reduce distances driven (e.g., urban planning, encouragement of people to use more public transportation, telecommuting, etc.).

Acknowledgments This research was supported by Sustainable Worldwide Transportation (http://www.umich.edu/ umtriswt). The authors wish to thank Brandon Schoettle (UMTRI) and Salla Salenius (VTT) for their assistance with gathering some of the relevant information. However, the authors are responsible for the final content and organization of this paper.

Open Access This article is distributed under the terms of the Creative Commons Attribution License which permits any use, distribution, and reproduction in any medium, provided the original author(s) and the source are credited.

\section{References}

1. Bjerre B, Thorsson U (2008) Is an alcohol ignition interlock programme a useful tool for changing the alcohol and driving habits of drink-drivers. Accid Anal Prev 40:267-273

2. Compton RP, Blomberg RD, Moskowitz H, Burns M, Peck RC, Fiorentino D (2002) Crash rate of alcohol impaired driving. In: Proceedings of the sixteenth International Conference on Alcohol, Drugs and Traffic Safety. Montreal: ICADTS

3. DaCoTA (2012) Road safety knowledge system. Retrieved on November 12, 2012 from http://safetyknowsys.swov.nl/Safety_ issues/Safety-issues.html

4. Department for Transport (2012) Statistics. Retrieved on November 14, 2012 from http://www.dft.gov.uk/statistics/

5. Elvik R, Høye A, Vaa T, Sørensen M (2009) The handbook of road safety measures, 2nd edn. Emerald Group, Bingley

6. ETSC (European Transport Safety Council) (2006) Intelligent speed assistance - myths and reality. Retrieved on December 4, 2012 from http://www.etsc.eu/documents/ISA\%20Myths.pdf

7. Euro NCAP (2012) Assessment protocol - safety assist, version 5.6. Retrieved on December 4, 2012 from http://www.euroncap.com/ files/Euro-NCAP-Assessment-Protocol--SA--v5-6--0-198765b7b3ee-4dde-9401-9b10d585dcce.pdf

8. European Commission (2012) Current speed limit policies. Retrieved on November 21, 2012 from http://ec.europa.eu/transport/road safety/specialist/knowledge/speed/speed_limits/current_speed_limit_policies.htm

9. Evans L (2004) Traffic safety. Science Serving Society, Bloomfield Hills

10. FOT-Net Wiki (2012) FOT catalogue. Retrieved on December 6, 2012 from http://wiki.fot-net.eu/index.php?title=FOT Catalogue

11. IIHS (Insurance Institute for Highway Safety) (2012a) Communities using red light and/or speed cameras. Retrieved on November 14, 2012 from http://www.iihs.org/ laws/cameramap.aspx 
12. IIHS (Insurance Institute for Highway Safety) (2012b) DUI/DWI laws. Retrieved on December 1, 2012 from http://www.iihs.org/ laws/dui.aspx

13. IIHS (Insurance Institute for Highway Safety) (2012c) Seat belt laws. Retrieved on November 30, 2012 from http://www.iihs.org/laws/ safetybeltuse.aspx

14. IIHS (Insurance Institute for Highway Safety) (2012d) Summary table: young driver licensing systems in the U.S. Retrieved on November 28, 2012 from http://www.iihs.org/laws/GraduatedLicenseCompare.aspx

15. IRTAD (International Road Traffic and Accident Database) (2012) Database including accident and traffic data and other safety indicators for 29 countries. Retrieved on November 12, 2012 from http:// internationaltransportforum.org/irtadpublic/about.html

16. Kallberg V-P, Törnqvist J (2011) Automaattisen nopeusvalvonnan tehostamisen mahdollisuudet [Improvement potential of the Finnish automatic speed enforcement system] (LINTU Reports 5/2011). Ministry of Transport and Communications, Helsinki

17. Koornstra M, Lynam D, Nilsson G, Noordzij P, Pettersson H-E, Wegman F, Wouters P (2002) SUNflower: A comparative study of the development of road safety in Sweden, the United Kingdom, and the Netherlands. SWOV, Leidschendam

18. Luoma J, Sivak M (2012) Interactions of environmental and safety measures for sustainable road transportation. Eur Trans Res Rev 4: 189-199

19. Magnusson P, Jakobsson L, Hultman S (2011) Alcohol interlock systems in Sweden. Ten years of systematic work. Am J Prev Med 40(3):378-379

20. NHTSA (National Highway Traffic Safety Administration) (2011) Traffic safety facts 2009. U.S. Department of Transportation, Washington DC

21. Nilsson G (2004) Traffic safety dimensions and the power model to describe the effect of speed on safety. Lund Institute of Technology, Department of Technology and Society, Lund

22. NTSB (National Transportation Safety Board) (2012) NTSB recommends ignition interlocks for all first-time DWI offenders and endorses development of passive alcohol-detection technology. Retrieved December 14, 2012 from http://www.ntsb.gov/news/2012/121211.html

23. OECD/ECMT. (Organization for Economic Co-operation and Development/International Road Federation) (2006) Speed management. Retrieved on November 26, 2012 from http://www. internationaltransportforum.org/Pub/pdf/06Speed.pdf

24. OECD/ITF. (Organization for Economic Co-operation and Development/International Road Federation) (2012) Road safety annual report 2011. International Transport Forum, Paris

25. Owens DA, Sivak M (1996) Differentiation of visibility and alcohol as contributors to twilight road fatalities. Hum Factors 38:680-689

26. Quimby A, Sardi GM (2004) Enforcement. In, European drivers and road risk-Part 1, Report on principal results (pp. 155-173). Paris: Institut National de Recherche sur les Transports et leur Sécurité (INRETS)
27. Sardi GM, Evers C (2004) Drinking and driving. In, European drivers and road risk-Part 1, Report on principal results (pp. 31-46). Paris: Institut National de Recherche sur les Transports et leur Sécurité (INRETS)

28. Sivak M (1996) Motor-vehicle safety in Europe and the USA: a public-health perspective. J Safety Res 27:225-331

29. Sivak M, Luoma J, Flannagan MJ, Bingham CR, Eby DW, Shope JT (2007) Traffic safety in the US: Re-examining major opportunities. J Safety Res 38:337-355

30. Sivak M, Schoettle B (2011) Recent major improvements in road safety in the U.S.: Changes in the frequency of crashes or the severity of the outcome of crashes? (Technical Report No. UMTRI-2011-46). Ann Arbor: The University of Michigan Transportation Research Institute

31. Sivak M, Tsimhoni O (2008) Improving traffic safety: conceptual considerations for successful action. J Safety Res 39: 453-457

32. Sullivan JM, Flannagan MJ (2002) The role of ambient light level in fatal crashes: inferences from daylight saving time transitions. Accid Anal Prev 34:487-498

33. SUPREME (Best Practices in Road Safety) (2010) Handbook for measures at the country level. European Union, Brussels

34. SWOV (2011) Fact sheet: Alcolock. Retrieved on November 28, 2012 from http://www.swov.nl/rapport/Factsheets/UK/FS_Alcolock. pdf

35. SWOV (2012) Data. Retrieved on November 14, 2012 from http:// www.swov.nl/UK/Research/Cijfers/information.htm

36. Thomas LJ, Srinivasan R, Decina LE, Staplin L (2008) Safety effects of automated speed enforcement programs. Trans Res Rec 2078:117126

37. Trafikanalys (2012) Statistik [Statistics]. Retrieved on November 14, 2012 from http://www.trafa.se/statistics/

38. Turbell T, Andersson T, Kullgren A, Larsson P, Lundell B, Lövsund P, Nilsson C, Tingvall C (1997) Optimizing seat belt usage by interlock systems (VTI särtryck 270). Swedish National Road and Transport Research Institute, Linköping

39. UN (United Nations) (2012) World statistics pocketbook 2011 (Series V, No. 36). Retrieved on January 6, 2013 from http:// unstats.un.org/unsd/pocketbook/Pocketbook\%202011.pdf

40. UNECE (United Nations Economic Commission for Europe) (2012) Statistical database. Retrieved on November 12, 2012 from http://w3. unece.org/pxweb/quickstatistics/readtable.asp?qs id $=12$

41. Wegman F, Oppe S (2010) Benchmarking road safety performances of countries. Safety Sci 48:1203-1211

42. WHO (2009) Global status report on road safety: time for action. World Health Organization, Geneva

43. WHO (2011) Global status report on alcohol and health 2011. World Health Organization, Geneva

44. WHO (2012) World health statistics 2012. World Health Organization, Geneva 